\title{
RESPONSE
}

\section{to the Keynote Address}

\author{
Robert E. Barnhill \\ Vice Chancellor for Research \& Public Service \\ President, Center for Research, Inc. \\ University of Kansas
}

I will begin with "strategic intent" and then work my way through Luis Proenza's main points.

\section{Strategic Intent}

"Strategic intent" (Hamel and Prahalad, Competing for the Future) has the attributes of direction, discovery, and destiny.

1. Direction: "Most companies are over-managed and under-led." That is, "more effort goes into the exercise of control than into the provision of direction." Delegation and empowerment, although desirable, are insufficient. "Better is creativity in the service of a clearly prescribed strategic intent."

2. Discovery: "Strategic intent should offer employees the enticing spectacle of a new destination or at least new routes to well-known destinations."

3. Destiny: "Only extraordinary goals provoke extraordinary efforts." Thus numerical goals are less energizing to employees than goals such as being the best in defined competitive areas.

\section{Tools to Achieve Strategic Intent}

Employees must be given the tools to achieve the strategic intent of their organization. In terms of university research, these tools include infrastructure, such as a smoothly running research administration office, and reasonable construction times of new laboratory space and acquisition of equipment. Hamel and Prahalad give the industrial example of Motorola and its formation of a corporate university for their employees to learn the tools of statistical methods, benchmarking, systems modeling, and teamwork. I can add to this example that Motorola University recently relocated to the Arizona State University Research Park so that ASU faculty could teach Motorola 
employees some of these techniques. Thus this example comprises a private company's collaborating with a public university in providing the tools for the company's employees.

Strategic intent goes beyond strategic planning. Strategic planning is a "feasibility sieve." Strategic intent goes beyond the feasible to what is barely possible, e.g., President Kennedy's vision of our landing on the moon.

Let me add to Luis Proenza's examples on strategic intent. In fact, I will build upon his privately mentioned example of the University of Utah in Salt Lake City. He mentioned that "the technology sectors in Salt Lake City account for $\$ 10$ billion in annual revenues and that five of the six key factors in the city's development as a technology center hinge on the University of Utah." His "spin-off company that has helped create more than 150 additional computer and software companies" is the Evans and Sutherland Corporation. "E\&S" was created around 1970 by David Evans and Ivan Sutherland. One of the best known of the companies due to this partnership is Silicon Graphics, started by Sutherland's Ph.D. graduate, Jim Clark.

At about the same time, Wayne Brown, Dean of Engineering, worked with President David Gardner to inaugurate the University of Utah Research Park. Their strategic intent was to develop a place where local entrepreneurship and expertise could flower. E\&S became the anchor tenant for this Park. The strategic intent of Dave Evans and Ivan Sutherland was to become the premier computer graphics research group in the country and they achieved that goal at the university. They then became the first tenant, and the anchor tenant, in the university's Research Park. These three elements of direction, discovery and destiny prevailed for all of these people, relative to their respective goals.

Let us take a second example. Luis Proenza mentioned Roger Geiger's signal book, Research and Relevant Knowledge. I would like to walk you through the example of the University of Arizona from that book. Some of you know that I spent a decade recently at Arizona State University, just down the road from the University of Arizona. So this time I am talking about a (former) friendly rival.

Arizona became a state, the forty-eighth, in 1912. It still feels like a frontier. On the eve of Sputnik, the University of Arizona was certainly a frontier with only two doctoral programs in arts and sciences and less than $\$ 1$ million of separately budgeted research. Today, the University of Arizona ranks in the top 10 public universities in research funding. What happened? 
Geiger says "the same factors that have been identified in the advancement of other research universities-establishing centers of research excellence, academic leadership, and the availability of resourceswere vital to Arizona as well." In 1959, President Richard A. Harvill "stated that Arizona's role in the expanding research economy would be to concentrate on fields in which it possessed some natural advantage." In the succeeding years two centers emerged, one in astronomy and one in anthropology. Each relied on natural advantages: astronomy on clear skies and nearby mountains for observatories, and anthropology on the presence of a large number of Native American tribal nations. The two corresponding departments became the first University of Arizona departments to receive national recognition in reputational rankings in 1966. Geiger discerns a pattern to establishing these research centers: (1) a natural advantage, (2) topics a little off the beaten academic path, (3) areas of excellence that had far-reaching effects on the rest of the university.

The University of Arizona's rise to research prominence flowered under President John Schaefer from 1971-1982. Long range planning with specific qualitative research goals required the selective treatment of departments. Schaefer's vision was to bring the university to a stature comparable to the members of the PAC 10 and Big 10. Within the university he devoted sufficient resources, including the allocation of indirect cost recovery, to stimulate additional research. Outside the university, research was sold as "economic development," a sure winner in frontier Arizona. Momentum and hard work by subsequent leadership have carried the University of Arizona to its present, prominent position.

\section{Lessons Learned}

The "lessons learned" by means of these examples are that strategic intent by the top leadership of the institution, coupled with natural advantages and local expertise can lead to research enhancement that lifts the entire institution.

Luis Proenza discussed three main points: (1) a "scan" of the U.S. R\&D environment, including its economic and sociopolitical aspects, (2) academic research competitiveness, including metrics, and (3) strategic questions that lead to "strategic intent."

\section{U.S. R\&D Environment}

I shall add a few items to Dr. Proenza's first point. Lester Thurow, MIT professor of management and economics, wrote the lead article in the June 1999, Atlantic Monthly, entitled "Building Wealth: The New Rules for 
Individuals, Companies, and Nations." Thurow writes, "a successful knowledge-based economy requires large public investments in education, infrastructure, and research and development." He quotes rates of return on R\&D as follows: private rates of return $24 \%$, public rates of return $66 \%$. Public rates of return indicate that benefits accrue to the whole society. "Put simply, the payoff from social investment in basic research is as clear as anything is ever going to be in economics."

Some sound bites:

$>50 \%$ of the economic progress in the U.S. since World War II has been due to technology developments.

> Alan Greenspan has stated: "the unexpected leap in technology is primarily responsible for the nation's phenomenal economic performance" (June 1999).

$>$ Internet economy: $\$ 300$ billion, 1.2 million jobs (June 1999).

$>$ Kansas jobs: average salary $\$ 25,495$; average salary in information technology $\$ 45,781$ (1997).

$>$ Information technology from the President's Information Technology Advisory Council report:

- $1 / 3$ of USA economic growth

- $1 / 3$ of all corporate R\&D

- $55 \%$ of all venture capital

- $45 \%$ of all corporate equipment investment

- New start-up every hour (90\% "fail")

- 7.4 million Americans in the information technology industry with $\$ 46,000$ average salary

- Catalyst for economic growth and prosperity

\section{Research Performance Measures}

Dr. Proenza's second point concerned academic research competitiveness.

There are a large number of performance measures for academic research. At the 1999 summer forum of the National Association of State Universities and Land Grant Colleges (NASULGC) involving its Council on Research Policy and Graduate Education (CRPGE), we spent 1 1/2 days on this topic. We heard from Hugh Graham, co-author with Nancy Diamond of the recent book. The Rise of American Research Universities, and from Charlotte Kuh, Executive Director of Science \& Engineering Personnel at the National Research Council. 
Performance measures are used to rank and rate universities nationally, as well as to provide accountability locally. Well-known rankings are performed by US News and World Report, by the National Research Council on graduate education, by the Carnegie Foundation on research, and in the book by Graham and Diamond. One dichotomy is between reputational and data-based rankings. Invoking Donald Stokes' book, Pasteur's Quadrant, I would call this a false dichotomy, but most people choose one or the other.

A principal reason that academic performance measures are important is that we will become what we decide to measure. Thus we should select and promote measures that reflect the values we believe are important.

Hugh Graham proposes that reputational rankings are an artifact of the storied past when there were only a few significant universities. In the Knowledge Age, with considerably more interdisciplinary work as well as institutional upward movement, there are no adequate peer reviews for the multitude of research universities. In particular, the academic discipline is among the categories that are inappropriate to use for rankings. The book by Graham and Diamond uses two main categories (federal research obligations and journal publications) with three sub-categories (publications in top-rated science and top-rated social science journals and top awards in the humanities). The book uses a per faculty capita approach. By contrast, the NRC graduate study reputational rankings book uses aggregate numbers in which, other things being equal, the larger the size of the department, the higher its ranking. Graham suggested the following criteria for future studies: journal citation density, top-journal approach, research funding, and outcome measures for doctoral graduates such as first jobs taken after graduation.

At the NASULGC forum, Charlotte Kuh spoke on the National Research Council's study of graduate education. It is clear from her presentation that there will be a future NRC report ranking graduate programs. Her most positive point is that the study represents an effort by the academy to establish rating standards. Her most negative point is that it damages some programs, which should not be damaged. Among the lessons learned from the last report are the following: give universities the opportunity to ensure that the NRC has used the correct data, and consider the audience(s). Unanswered questions include how to handle interdisciplinary areas; how to recognize that more than $50 \%$ of our Ph.D. graduates do not go into university positions; and how to recognize the diversity of universities' missions. 
A view that came from much of the discussion is that rankings are valid for perhaps the top 20 universities. For universities in the middle, relatively small changes in the data or the criteria can produce dramatic differences in the rankings ("computational instability").

An alternative set of criteria was presented by Anthony Boccanfuso, Pricewaterhouse Coopers LLP, who advises universities on how to identify peer institutions. The criteria are the following: federal R\&D obligations and expenditures (55\%), endowments per faculty, number of faculty, and licensing income. These are publicly available numbers.

Joan Lorden and Lawrence Martin will develop a paper from the results of this forum. After some subsequent discussion, the CRPGE membership will forward an accepted set of resolutions to the appropriate rankers. In addition to this effort, NASULGC has formed a Measurements Working Group.

\section{NASULGC Measurements Working Group}

This working group, chaired by President Martin Jischke, lowa State University, seeks to bring a "NASULGC" perspective to the issue of measurements and rankings. It particularly would like to replace the US News and World Report approach with something that would measure the value added by universities and not focus on inputs only. The working group has met by conference phone call and concurred with the following statement of values:

As public, state and land grant institutions, we value:

1. Access to our programs and services;

2. Programs of study that are both liberal and practical in their character;

3. Both basic and applied research;

4. Engagement with our communities through extension, outreach and other partnerships;

5. Effective and efficient use of resources in adding educational value to those we serve;

6. The public character of our governance and support.

(Emphasis added)

The members of the committee have mailed to President Jischke the mission statements and what could be called performance indicators for their own institutions. Data from additional institutions would be useful. 


\section{Example of Performance Measure: Kansas Research Numbers}

In Kansas, the three research universities were recently asked for their "research numbers." We interpreted this to mean numbers such as the R\&D expenditures compiled each year by the National Science Foundation (NSF) from the 500 research universities, so we took the "NSF numbers" as our starting point. Because the NSF discriminates against disciplines by counting only science and engineering, we added the excluded disciplines. Finally, we also added expenditures from training grants, because we feel these have two equally important missions, research and education. These adjusted totals, which we call the "enhanced NSF numbers," will be used in the future in Kansas to measure our research performance.

\section{Concluding Remarks}

Last summer Michael Crow reminded us that we are the architects capable of designing (or re-designing) our institutions. He left us with the paramount challenge to determine our goals and the processes by which we will achieve them.

Luis Proenza has presented the national R\&D environment, research competitiveness, and models of collaborations. With strategic intent, we can set and achieve goals.

Our challenge is to set in motion change, and the resulting legacy of achievement, analogously to the accomplishments of David Gardner, Wayne Brown, David Evans, and Ivan Sutherland at the University of Utah and Richard Harvill and John Schaefer at the University of Arizona. 